\title{
LAS REDUCCIONES DE INDIOS DURANTE EL PERIODO COLONIAL TEMPRANO EN LOS ANDES CENTRALES (SS. XVI-XVII). REPRESENTACIONES DEL ESPACIO SOCIAL, SIGNIFICANCIAS RELIGIOSAS Y CONTROL POLÍTICO
}

\author{
Andrea Gonzales Lombardi
}

Instituto de Estudios Peruanos

\begin{abstract}
RESUMEN
Se revisan las investigaciones que a través de las fuentes históricas analizan el manejo del espacio y transformaciones en asentamientos locales causadas por la institución de las reducciones durante el Periodo Colonial Temprano en los Andes Centrales. Ampliando el enfoque, se propone una aproximación arqueológica que examina el fenómeno a partir de indicadores materiales; enfocándose en las relaciones entre procesos de dominación/resistencia política y el surgimiento de comportamientos sincréticos/ antagónicos. Finalmente, se trata el caso de la doctrina colonial de la "Limpia Concepción de Marcapomacocha", en Junin; presentando la evidencia arqueológica registrada durante el trabajo de campo.
\end{abstract}

PALABRAS CLAVE

Periodo Colonial / Reducciones / Doctrinas / Junín / Asentamientos

\begin{abstract}
This presentation examines previous works that, based in historical evidence, explore the spacial distribution and physcial transformations in local settlements caused by the institution of reducciones during the Early Colonial Period in the Central Andes. Strengthening the scope of the research is proposed an archaelogical approach that analyses this phenomena based in material evidence. Specifically, the research focus is the relationship between processes of politic dominance/resistance and the emergence of syncretic/antagonistic behaviors. Finally, we approach to the case of the "Limpia Concepción de Marcapomacocha", a colonial doctrina in Junin, presenting the archaeological evidence recorded during fieldwork.
\end{abstract}

\section{KEYWORDS}

Colonial Period / Reducciones / Doctrinas / Junin / Settlements. 
para deprender a ser cristianos, tienen [los indios] primero necesidad de saber ser hombres y que se les introduzca el gobierno y modelo de vivir político y razonable. Francisco de Toledo, 1965, p. 262

De la cita anterior se desprende lo que fue la justificación con la que la Corona Española impuso su presencia en América, y en particular en los Andes Centrales: la misión evangelizadora. Bajo esta idea, la conquista obedecía al fin supremo de la salvación de las almas de los "indios"; sin embargo, más allá de garantizar la vida bajo las creencias católicas, las campañas evangelizadoras y el establecimiento de doctrinas y reducciones implicaban el despliegue de políticas de control social y económico de los pueblos andinos prehispánicos. Con la llegada de los españoles al Nuevo Mundo se inició un largo y complejo proceso de contacto cultural, en el que las estructuras sociales tanto de conquistadores como conquistados se verían profundamente transformadas (Spalding, 1974).

Así es que la fundación de los pueblos de indios o "reducciones" y las campañas evangelizadoras fueron las piedras angulares para consolidar la conquista de lo que fuera el Tawantinsuyo.

La experiencia de la colonización española tuvo sus primeros ensayos con los pueblos del actual México, y antes en tierras moriscas durante la Reconquista; sin embargo, el aplicar el modelo reduccional a los Andes Centrales supuso una readaptación de los modelos preconcebidos por los españoles; no sólo a una variada y extrema geografía, sino también a una realidad social y política muy particular a la región. En este sentido es preciso señalar que aunque la traza ortogonal delimitada por muros, era el modelo idealmente propuesto en la Real Cédula de 1549 para la edificación de los pueblos de indios; debido a factores como la gran dispersión de los grupos locales en el territorio y la agreste geografía de las cordilleras andinas, muchos asentamientos coloniales resultaron como una suerte de "híbridos" entre las formas de organización local y foránea (Gutiérrez 1993).

Pero ¿por qué es importante el análisis de estas formas de asentamiento? ¿Al estudiarlas podremos comprender mejor el proceso de conquista de los Andes Centrales? Más aún, ¿Es posible identificar en ellas representaciones físicas de las relaciones de dominación, resistencia y coexistencia de los grupos locales y foráneos; es decir, evidencias de la materialización de la colonización? 
Estas preguntas han sido abordadas por recientes investigaciones. La denominada "Arqueología Histórica" ha cobrado notable importancia en las discusiones acerca de temas como dominación, resistencia, colonialismo, identidad, entre otros. Precisamente, en 2010 se realizó el "Simposio Internacional de Arqueología Histórica", organizado por la Universidad Ricardo Palma; uno de los primeros encuentros en los que se discute desde la evidencia material, la problemática de la conquista y colonización de América. Asimismo, en octubre de 2013 se presentaron y discutieron en la Universidad Católica los trabajos de J. Mumford, Vertical Empire; the General Resettlement of Indians in the Colonial Andes; S. Wernke, Negotiated Settlements; Andean Communities and Landscapes under Inka and Spanish Colonialism; y M. Zuloaga, La conquista negociada: guarangas, autoridades locales e imperio en Huaylas, Perú (1532-1610). Ese mismo año, el curso de Andes VII, que trata acerca del Periodo Colonial, es incorporado a la malla curricular de la carrera de Arqueología en la Universidad Nacional Mayor de San Marcos.

Esto muestra que el campo de la arqueología está ampliándose hacia temas que antes eran tratados exclusivamente por historiadores, haciéndose a un lado la idea de que ella debía ocuparse únicamente del estudio de los periodos pre-hispánicos. Dicho avance es sumamente valioso pues los trabajos acerca del tema han demostrado que el estudio arqueológico de los Andes Centrales durante el periodo colonial no sólo permite conocer mejor a los grupos foráneos que llegaron a partir del siglo XVI; sino también otorga un nuevo enfoque de las sociedades locales, presentándolas como un agente activo en el proceso de conquista.

\section{IDENTIDADES ÉTNICAS Y SUS REPRESENTACIONES EN LOS ANDES CENTRALES DURANTE EL PERIODO COLONIAL}

Los grupos sociales expresan constantemente su identidad a través de manifestaciones materiales; elementos tan básicos como la vestimenta, los modos de preparación de los alimentos, hasta las formas arquitectónicas, el manejo del espacio y los propios conceptos acerca del mismo son claros factores que conforman la identidad colectiva de una sociedad. En este sentido, entenderemos identidad étnica como:

El aspecto de la auto-conceptualización de una persona que resulta de la identificación con un grupo mayor en oposición a otros en la base de diferenciaciones culturales percibidas y/o descendencia común. (Jones, 2003, xiii) [Traducción nuestra] 
Sin embargo, es en un contexto de contacto y confrontación con otro grupo (como en el caso de la conquista española de los Andes Centrales) que los elementos que definen la identidad e intervienen en su expresión material, pueden ser más fácilmente identificados (Sillar y Dean 2002). Con la expansión del imperio inca a inicios del siglo XV, numerosos grupos locales que habitaban las regiones conquistadas, fueron trasladados y reasentados como mitimaes. Ello caracterizó al Tawantinsuyo como un territorio de confluencia de múltiples identidades, un mosaico de grupos étnicos que interactuaban bajo las normas establecidas por el imperio inca. Este habría sido el panorama que hallaron los españoles al incursionar en estas tierras, y con su llegada, dicho contexto multiétnico se complejizó aún más; ya no sólo era la identidad(es) local(es) frente a la fuerza imperial, surgía una nueva identidad: la del "indio". Como resume Huertas:

Los incas y españoles desarticularon el viejo panel étnico; los primeros al aplicar éxodos coercitivos a los pueblos vencidos, los segundos al desarticular viejos curacazgos y al comprimir parcialidades en un solo núcleo poblacional o reducción. Estos desplazamientos poblacionales explican en muchos casos la estructura plural de los asentamientos humanos. (Huertas, 1991, p. 499)

Entonces, para nuestro tema de interés, la recreación de una sociedad y de la identidad de la misma, puede verse representada en las formas arquitectónicas de sus asentamientos, así como en el manejo del espacio al interior y alrededor de los mismos. Esto es de especial relevancia en los Andes Centrales previos a la conquista española, donde la arquitectura no representaba una "separación" del espacio geográfico; por el contrario, a través de ella los grupos pre-hispánicos buscaban integrarse con la naturaleza, a la que asociaban con puntos de origen o de paso de ancestros míticos (Gose. 2008, 2006,1996; Glowacki y Malpass, 2003; Duviols, 1977) en los cuales las momias personificaban la soberanlu00eda pollu00edtica y controlaban la fertilidad de la tierra al igual que los esplu00edritus de cerros actuales. Sin embargo, los antiguos antepasados cumplieron estas funciones como fundadores de grupos particulares de descendencia (ayllus

Esta práctica religiosa generó que el paisaje, concebido como parte del espacio social, simbolizado y percibido, representara un importante referente de identidad para los pueblos prehispánicos, determinando relaciones de parentesco, labor comunitaria y pertenencia a un territorio (MacCormack, 2004, 1991; Urton, 1984)" given": "Sabine", "nondropping-particle": “” 
Al hablar de materialidad de las espacialidades me refiero a la cultura material socialmente inserta en un espacio, tanto la infraestructura física fija (como por ejemplo la arquitectura), como los objetos muebles que ayudan a construir el significado de ese lugar o paisaje. Por supuesto, una espacialidad está también integrada por rasgos físicos naturales que pueden estar incorporados como elementos constitutivos de ese espacio social, y cargados de significado. (Acuto, 1999, p. 34, nota 1).

Así, a un nivel más específico, cada grupo humano que se concebía como unidad definía en el espacio sus propios "centros" y los cargaba de un significado y funcionalidad particular; estableciendo sus asentamientos y organizándose a nivel político, social y económico (Urton 1984 para el caso de los ceques en Cuzco).

\section{UN NUEVO ORDEN COLONIAL}

Durante varias décadas, los estudios acerca de la conquista presentaban a los indígenas como sumisos y suprimidos bajo un orden radicalmente autoritario, que los dejaba como un grupo sin voluntad de pensamiento o reacción. Ahora se conoce que los indígenas eran capaces de hacer más que sólo rechazar (con las consecuencias que ello implicaba) o aceptar las formas de vida impuestas por los españoles; por el contrario, como afirma (Estenssoro, 2001), el contexto social durante este periodo puede entenderse mejor si se analiza en términos de relaciones de "fusiónasimilación" y "rechazo-separación". Esto quiere decir que, en busca de su supervivencia cultural, ambos grupos, indígenas y españoles, se vieron en la necesidad de acercarse entre sí, conocerse y expresarse en términos del otro:

están tan interesados [los indígenas] en conservar sus antiguos ritos como en conocer los ritos católicos y las características del nuevo dios, ya sea para poder domesticarlo y hacerlo favorable a ellos, ya sea para combatirlo o contrarrestar su poder, ya sea finalmente para reproducir la religión católica sin necesidad de pasar por la intermediación de los españoles. (Estenssoro, 2001, p. 458)

Este deseo de conocimiento mutuo entre locales y foráneos devino en el surgimiento de nuevas expresiones religiosas, andino-católicas; uno de los más conocidos es el surgimiento de movimientos revitalistas como el inkarri o taquionqoy. Similarmente, se dio la asimilación de elementos 
de los cultos católicos como parte de las creencias y rituales andinos. Y precisamente, el espacio de las reducciones o pueblos de indios fungió como uno de los escenarios en el que ambas tradiciones co-existieron y se fusionaron; desplegando sus propios conceptos acerca de la concepción del espacio y cómo este debía ser organizado.

Como un ejemplo de ello podemos señalar los conceptos de dualidad y tripartición. Dichos conceptos eran un elemento sustancial que regía la concepción prehispánica del orden divino; el mismo que se replicaba en el mundo humano a través de la ubicación y disposición de los centros ceremoniales y urbanos, y en la organización social y económica de los grupos. Por el lado contrario, el damero de los pueblos españoles y de los de Europa en general, representaba una concepción del mundo en un orden centro-periferia, en el que el primero tiene poder autónomo y total frente al segundo; relación similar a la del sistema monárquico por el cual se regían. Ahora, aunque el concepto de "centro" también formaba parte de la cosmovisión andina, más allá de la caracterizarse como indicaría la palabra, central y único, este era representado por una multiplicidad de centros: excéntricos, opuestos y complementarios (Acuto, 1999)prlu00e1cticas y relaciones sociales particulares. De alguna manera, la estructuracilu00f3n del espacio social, tanto refleja como condiciona la estructuracilu00f3n de la sociedad.|’'np. 34: |" Dentro de los que Soja (1996).

Estas significaciones opuestas y adscripciones al espacio reflejan más aspectos que exclusivamente la relación con un lugar de culto o residencia, en ellas se codifican normas sociales (Durston, 1999); las mismas que desde la llegada de los españoles al Nuevo Mundo se irán entrelazando progresivamente en un proceso de "transculturación" (Ortiz citado por Beals, 1965).

Esta interacción espacio social-comunidad(es) constituyó un regulador substancial para el establecimiento, reafirmación y transformación de las relaciones sociales entre distintos grupos de indígenas y españoles (y entre los miembros de cada uno de ellos). Del mismo modo, la configuración morfológica y la espacialidad de una zona de ocupación se veían transformados por las mismas relaciones sociales que generaban (Acuto, 2008). De ello también, que el apropiarse del espacio físico, social y transformar los referentes simbólicos religiosos de un pueblo en particular representaba un eficaz medio para el control de sus habitantes. 
Uno de los medios para lograr dicha apropiación fueron los rituales; que haciendo uso de la parafernalia religiosa y sus representaciones simbólicas, tienen la finalidad de controlar a los pueblos dentro del territorio dominado. Al homogeneizar la ideología religiosa se homogeneiza por igual la concepción acerca del orden en el que el mundo debe de funcionar, lo que incluye tener el control sobre o ser controlado por otros grupos sociales (Spalding, 1999).

\section{EL SURGIMIENTO DE LAS REDUCCIONES DE INDIOS EN LOS ANDES CENTRALES}

El choque entre los sistemas culturales prehispánico y español generó una fuerte crisis en el primero, lo que se vio expresado en la caída del Imperio Inca, y en una reforma de los sistemas económico, social y religioso que venían funcionando hasta entonces. Por esto, es que, casi inmediatamente a su llegada al Nuevo Mundo, la Corona española toma como medida para el reordenamiento y educación de los indios, el establecimiento de las reducciones, con la consiguiente evangelización de los mismos (Duviols, 2003). Esta política fue implantada por todo el largo y ancho de lo que fuera el otrora Tawantinsuyo. Sin embargo, el temprano intento por establecer el nuevo orden no fue correctamente planificado, por lo que no tuvo más que un efecto contrario al deseado, pues los indígenas continuaban viviendo bajo sus preceptos y creencias religiosas (Duviols, 1977).

La situación cambiaría hacia 1570, año en el que por mandato del virrey Toledo, surge lo que se conoce como Nueva Extirpación (Duviols, 1986), así surgen y se institucionalizan los cargos de curas doctrineros y de extirpadores de idolatrías quienes, con la finalidad de lograr la salvación de los indios llevarían a cabo intensas búsquedas de los ídolos y wakas adorados por los nativos, destruyendo así cualquier presencia del "demonio" en la tierra. Esta campaña extirpadora vino de la mano de una profunda reorganización del sistema reduccional, que implicó grandes movimientos poblacionales que alteraron completamente la configuración demográfica de la región.

Mas a pesar de todos los intentos desplegados, lo cierto era que los indígenas aún evadían el control español al escaparse de las reducciones y refugiarse en sus antiguos asentamientos.

Por ello, a partir de 1610 fueron los extirpadores quienes tomaron el asunto en sus manos, haciéndose cargo no sólo de la evangelización, sino 
también del control de los indígenas en las reducciones. Es así que estos movimientos de los indios hacia las afueras de las reducciones generan el surgimiento de los "pueblos viejos", estancias y otros asentamientos, inevitablemente más alejados del control de las autoridades coloniales.

En el presente trabajo, proponemos el caso del pueblo de indios de "La Limpia Concepción de Marcapomacocha" como un caso a ser estudiado, puesto que fue una cabeza de doctrina, sin llegar a ser propiamente una reducción. Antes revisaremos brevemente el surgimiento del sistema de reducciones

\section{LAS REDUCCIONES DE INDIOS COMO ESPACIO SOCIAL}

A pesar del extenso registro etnohistórico que los soldados, cronistas y evangelizadores realizaron durante los siglos XVI al XVIII en los Andes Centrales acerca de la fundación de los pueblos de indios, reducciones y doctrinas; en comparación son relativamente escasos los trabajos en los que se aborde el análisis de los asentamientos o espacios sociales coloniales a partir de la evidencia material, entre ellos. Destacan sin embargo, los trabajos de (Durston, 1999), quien analiza las reducciones como sistema espacial y referente de identidad para los grupos que las habitaban; (Gade, 1992), (Gade \& Escobar, 1982) discuten acerca de los nuevos elementos culturales asimilados por los grupos locales en los Andes Centrales; (Rice, 2012) excava la reducción de Torata Alta en Moquegua. Recientes investigaciones también abordan el tema del espacio reduccional como producto de relaciones de resistencia, asimilación y fusión de los elementos católicos y andinos pre-hispánicos: (Gutiérrez et al., 1993), Mumford (2012), Van Valkenburgh (2012) y (Wernke, 2013, 2007,2006, 2003).

Ejemplos concretos los hallamos en los casos de las plazas de los pueblos de indios, pues ellas pasan a ser espacios festivos, religiosos y de carácter administrativo, cualidades que no se presentan en aquellas de plazas de España. Estas festividades además se hallaban estrechamente relacionas con celebraciones o jornadas comunales de trabajo. Por ejemplo, Urton (1984) registra en el pueblo de Paqarictambo divisiones sociales, de parentesco y de labor en torno a y para el cuidado de los muros que rodean la plaza del pueblo (que posee dos plazas). Estas divisiones o espacios de labor comunal designados, a los que él llama chutas provendrían de formas de organización, sino completamente prehispánicas, de origen colonial. 
De especial interés resultan los trabajos de Gutiérrez (1993)la ciudad hispanoamericana se irlu00e1 configurando en un proceso de ensayo-error-correccilu00f3n que se vislumbra en dos hechos sintom u00e1ticos: la frecuencia de los traslados de ciudades y la formulaci u00f3n de una normativa en las Ordenanzas de Poblaci\u00f3n de Felipe II (1573, quien menciona casos concretos acerca del tema. Por ejemplo, la plaza de Coporaque, en Cuzco; donde se observa que "los ocho arcos que flanqueaban la plaza son indicativos de los sitios de acceso de las comunidades barriales para la festividad religiosa patronal..." (Gutiérrez 1993, p. 32). Asimismo, también destaca la utilización de capillas abiertas, con grandes retablos y balcones destinados para la evangelización de los indios; quienes en tiempos pre-hispánicos ya veían las plazas como espacios de carácter sacro (Op. cit.).

En muchos casos, otro elemento arquitectónico de las iglesias, las torres, eran mantenidas a través de las donaciones y el cuidado de los distintos "barrios", cada uno asociado a una torre en particular; modelo muy similar al de la repartición de las labores comunales por ayllus.

Otro ejemplo representativo de la fusión de rasgos católicos e indígenas es el que presenta Durston (1999), en donde se observa la presencia de tres templos. En este caso, la iglesia mayor representa un punto divisorio entre dos espacios distintos pero complementarios (que podrían corresponder a barrios o ayllus), como ocurre en Pomata y en Zepita. En casos extremos, como Anco-Cala (Oruro), los únicos elementos españoles que permanecen son la iglesia y el atrio; el resto del asentamiento se organiza en dos conjuntos dispersos y de traza irregular, separados por el espacio delimitado por la iglesia (Op. cit.).

Ampliando el panorama, el modelo de Tolerancia Antagonista (Hayden, 2002) propone la existencia de una fuerte relación entre el establecimiento de la dominación política a nivel regional y el desarrollo a largo plazo de comportamientos sincréticos entre miembros de distintas comunidades religiosas potencialmente antagonistas. Estos comportamientos se manifestarían materialmente a través de cuatro indicadores: 1) Altura o visibilidad, 2) expropiación o reorientación, 3) centralidad, y 4) Superposición de estructuras.

Aunque este modelo sólo ha sido aplicado para regiones de Europa Oriental e India (Hayden, 2005, Hayden et. al., 2011), estudios preliminares 
permiten suponer su aplicabilidad a los Andes Centrales, puesto que es una región igualmente sometida a un largo proceso de dominación imperial; inca y española. Cabe destacar que dentro de la propuesta del modelo de antagonismo y tolerancia se plantea expandir el análisis de las relaciones entre los grupos de conquistados y conquistadores más allá de la dicotomía entre "dominación" y "resistencia" (Hayden, 2002). Esto permitiría comprender mejor la dinámica de los procesos de conquista de larga duración.

Así, lo que realmente cobra importancia en esta interacción entre ambos sistemas simbólicos, es el significado tras la forma. El paso de los pueblos prehispánicos a los asentamientos coloniales no solo traía consigo cambios puramente formales en el espacio; por el contrario, en este proceso se gestó una compleja, e irreversible, transformación que trastocó cada aspecto de la vida de los pueblos indígenas (Durston, 1999).

Más allá de la propia traza del asentamiento, lo importante era la relación del mismo con el paisaje circundante, su (re)conexión con los ancestros y pacarinas de tiempos prehispánicos. Esto se materializó a través del ritual, que, bajo formas católicas, mantenía y reafirma las relaciones entre los ayllus o parcialidades y sus divinidades. Es, en última instancia, el ritual el que legitima el paisaje. Por ello, las reducciones no significaron, al menos no en la práctica, una ruptura definitiva, un espacio radicalmente opuesto a las concepciones andinas del mundo.

\section{LA DOCTRINA DE LA LIMPIA CONCEPCIÓN DE MARCAPO- MACOCHA DURANTE EL SIGLO XVII; UNA PROPUESTA DE ESTUDIO}

Una doctrina era principalmente de carácter eclesiástico, aunque también ejercía claras funciones económicas; se distinguía de las misiones o de las reducciones por ser una delimitación territorial, un concepto "jurídico- administrativo- civil". Se componía principalmente por 1) un territorio, 2) varias iglesias, el número variaba dependiendo de la cantidad de pueblos que conformaban la doctrina, 3) los sacerdotes y 4) los feligreses (León, 2008: 82-83). Cabe resaltar que, al contrario de lo que la idea de unidad territorial puede transmitir, "Una doctrina estaba formada por varios pueblos pequeños, distantes entre sí, y hacía de cabecera de doctrina el más importante de ellos, donde residía el cura doctrinero." (Aparicio, 2001, p. 28). 
La doctrina de La Limpia Concepción de [Marca]Pomacocha se ubicaba en el corregimiento de Canta. Dicho corregimiento como menciona Villar Córdoba (1935) quedó fundado hacia 1535 bajo el nombre de "Villa de la Purísima Concepción de Canta", abarcando parte de la costa y sierra de Lima. De acuerdo a las descripciones de Vázquez de Espinoza (citado por León, 2008, p. 63), el corregimiento contaba con veinte pueblos en cinco repartimientos. Los límites para aquel tiempo los conformaban las provincias de Tarma, Chancay, Huarochirí y el Corregimiento del Cercado. Canta poseía, en ese entonces, nueve curatos, entre ellos; Pomacocha. Sin embargo, cabe señalar el mismo habría pertenecido antes a la Doctrina del Valle de Caujo, hacia el Este de Canta (Aparicio, 2001).

Pomacocha adoptó luego el nombre de (Marca)Pomacocha; y siglos más tarde quedaría registrado en los documentos coloniales como La Purísima Concepción de Marcapomacocha (Op. cit.). Cabe señalar que dicho pueblo, a pesar de ser una cabeza de doctrina, no era lo que formalmente se conocería como una reducción de indios. Más aún, la información provista por el censo realizado por Toribio de Mogrovejo a inicios del siglo XVII nos describe un asentamiento pequeño que apenas llega a las 70 personas (Benito, 2006: 265). Asimismo, un documento del Archivo del Obispado de Huacho refiere que Santa Bárbara de Carhuacayán, un pueblo anexo a Marcapomacocha "[es] de mayor feligrecia que Pomacocha, cabeza de doctrina, pues apenas en él hay seis familias...” (AOH, 1769, Leg. 4, Exp. 10).

Actualmente, Marcapomacocha es una comunidad campesina, capital distrital de la provincia de Yauli, perteneciente a la región Junín, en la que la actividad ganadera y la crianza de truchas son las principales actividades. También se hallan minerales metálicos en los cerros aledaños a la comunidad, de hecho, se están iniciando exploraciones mineras en el Cerro Monterrico, al Norte de la laguna de Marcacocha, en los que habría yacimientos de plata.

Apenas a unos pocos kilómetros al Este del pueblo de Marcapomacocha se encuentra la Cordillera de la Viuda, vía de paso hacia Canta y toda la parte alta de la cuenca del Chillón, que nace de la laguna Chuchún, al Noroeste del distrito. Algunos de los cerros alrededor del pueblo son el Rajuntay y Ninarupa (en la Cordillera de la Viuda), Monterrico, Huarmitayana, Jinterpunta, Paclas, Julcán, y Mishipañawi (en la estancia de Huamanmarca). Las principales lagunas son tres: Marcapomacocha, Marcacocha y Antacoto (Ver Fig. 1). 


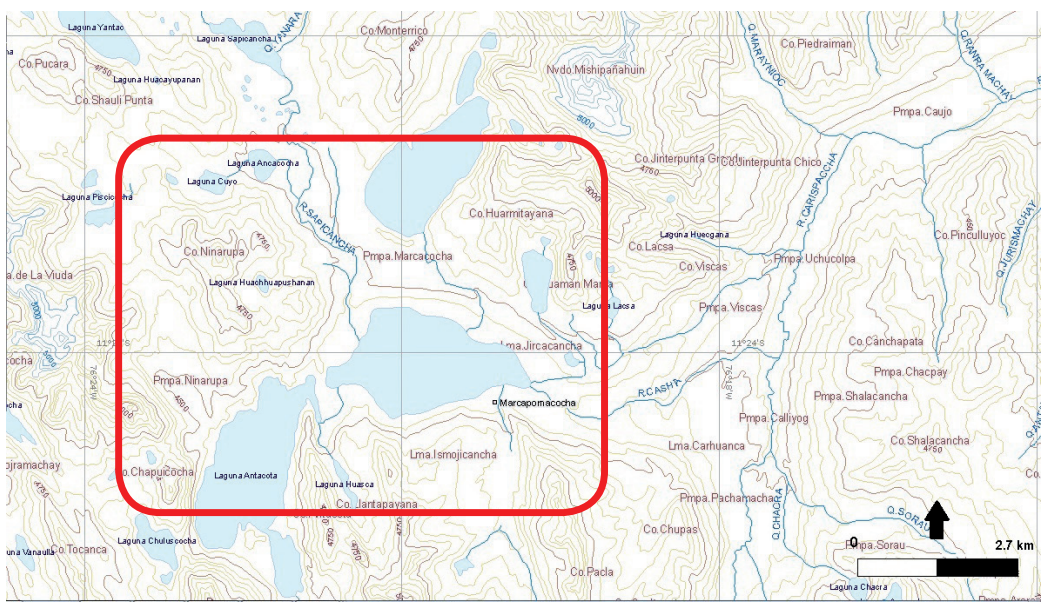

Figura 1. Vista general del área de estudio. CN 23-K, Ondores.

Al llegar al pueblo, se puede observar que la plaza actual de Marcapomacocha aún conserva planta trapezoidal, forma característica de asentamientos Inca (Hyslop, 1990). El reconocimiento de la iglesia moderna resultó especialmente valioso, pues en la torre de la misma se registraron dos campanas con grabados de los años 1649 y 1670. Igualmente destaca que la edificación presenta el eje central paralelo a la plaza; lo que permite suponer que bajo las bases de la construcción moderna, pudo haberse ubicado una iglesia colonial, adyacente a una plaza Inca (Ver Fig. 2). La evidencia comparativa de casos registrados por el Proyecto Qhapaq Ñan nos habla acerca de iglesias coloniales como indicadores de asentamientos y caminos Inca (Casaverde 2012); por ejemplo, los casos de Copa y Cajatambo, en la sierra de Lima. Como lo resume Casaverde:

Su disposición [de la iglesia] coincidía con el planeamiento Inca, ya que los templos, Ushnu, y otras estructuras de carácter religioso se hallaban agrupados alrededor de las plazas Inca, sectores desde donde divergían y convergían a la vez los caminos Inca. (Casaverde, 2012).

Destaca también que la planta de la iglesia presenta la sacristía en posición lateral en relación a la nave, algo común para templos coloniales. Las características estilísticas observadas al interior de la estructura no se asemejan a aquellas propias a una iglesia católica moderna; quizás al momento de remodelarla se mantuvo el patrón estilístico de la iglesia anterior. 


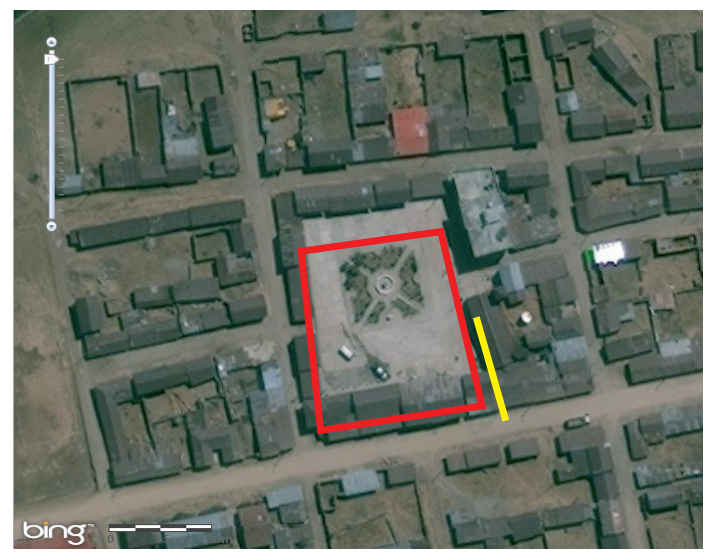

Figura 2. Detalle de planta, plaza de Marcapomacocha (en rojo). Nótese la forma trapezoidal y la variación en el eje de la iglesia (en amarillo). Fuente: Google Earth

Estos elementos nos permiten proponer la existencia de una ocupación colonial bajo los cimientos modernos del pueblo de Marcapomacocha. Sin embargo, la distribución general del pueblo, sugiere que la traza del asentamiento colonial fue irregular y no correspondía a una planta ortogonal típica de las reducciones; acercándose más a la distribución espacial de un pueblo de indios de menor extensión.

Por lo presentado aquí, sugerimos que Marcapomacocha habría sido un pequeño pueblo de indios que se va conformando hacia inicios del siglo XVII, con un bajo número de habitantes. Sin embargo, no se encontraba aislado del resto del sistema de asentamientos coloniales, pues habría sido un paso obligatorio para los que recorrieron el camino desde la sierra de Lima hacia la región de Tarma. A partir del contraste de los datos obtenidos mediante los análisis cartográficos, la identificación de los lugares mencionados en los documentos coloniales revisados (AAl 1650; AOL 1774, 1769), la revisión de mapas antiguos y el registro arqueológico; sugerimos que es posible identificar un camino Inca que diverge por ambas márgenes de la laguna Marcapomacocha; el primero pasaría por el pueblo moderno, pasando cerca de la iglesia; el otro, por la loma de Jircacancha. Partiendo de estos datos, creemos haber identificado una ruta que va desde la Cordillera de la Viuda hacia Chacamarca. Este camino habría sido reutilizado durante 
tiempos coloniales, uniendo las estancias y doctrinas rurales desde Canta, pasando por las pampas de Junín, hacia el valle del Mantaro (Ver Fig. 3).

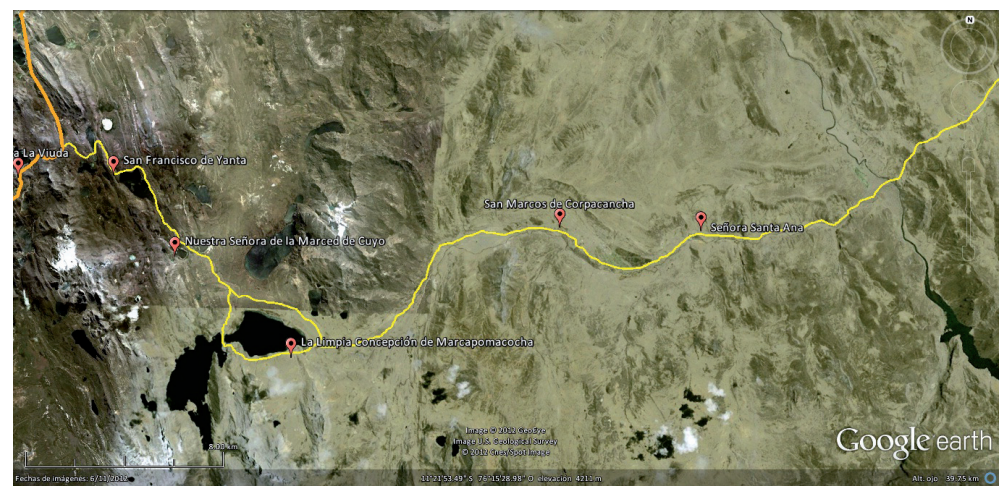

Figura 3. Posible ruta del Camino Real, paso desde la Cordillera de la Viuda hacia el valle del Mantaro.

El estudio de la secuencia ocupacional y distribución espacial de los asentamientos pre-hispánicos y coloniales en Marcapomacocha resulta interesante para la arqueología histórica, puesto que gran parte de las investigaciones se centran en reducciones; asentamientos típicamente españoles, con traza ortogonal y que abarcaban una gran cantidad de indios. Mientras que gran parte de los asentamientos en los Andes Centrales no presentaban las características típicas de las reducciones.

Profundizar en los aspectos aquí esbozados nos puede permitir comparar registros arqueológicos de distinta escala, e interpretarlos en relación a las expresiones religiosas que prevalecieron en el lugar. Ello a su vez permitiría contrastar los contextos sociales que se dieron en distintos lugares durante el Periodo Colonial, y lo que esto implicó para la pervivencia de las prácticas religiosas asociadas al espacio de los pueblos coloniales y al medio circundante. No es difícil imaginar que si aún en las reducciones más controladas por el régimen español los indígenas encontraban la manera de continuar desarrollando sus prácticas religiosas; en los pueblos alejados y dispersos la tarea evangelizadora y extirpadora resultaba mucho más compleja. Sobre todo en una región con una larga secuencia ocupacional pre-hispánica como lo es Marcapomacocha (Gonzáles y Astuhuamán 2012 basados en Parsons 2000). 
Siguiendo esta línea de investigación, proponemos abordar el caso de Marcapomacocha, desde una perspectiva histórica, que analice el proceso social ocurrido desde el Periodo Intermedio Tardío (1000-1420 d.C.) hasta el Periodo Colonial Temprano (1570-1650 d.C.), dejando a un lado la dicotomía entre dominación y resistencia.

Finalmente, aunque no existe investigación previa de este caso en particular, se han desarrollado trabajos acerca del patrón de asentamiento en otras áreas de la región Junín (Matos, 1994; Parsons et al., 1997; Matos, 1997; Parsons et al., 2000). Esta información será utilizada como referencia comparativa para los sitios registrados. Asimismo, hemos recolectado registros de curas doctrineros, viajeros y exploradores que describen el área (AAL 1650; AOH 1774,1769; Bueno 1951; Aparicio, 2001). El uso de distintas fuentes de información permitirá abordar las discusiones antropológicas acerca de la co-existencia de grupos antagónicos en un espacio en común; para contrastarla con las evidencias materiales identificadas en Marcapomacocha.

La reconstrucción del asentamiento colonial y el estudio del contexto social, político y religioso de Marcapomacocha constituirán un valioso aporte para la arqueología y antropología de una región y periodo aún en ascenso en la literatura académica.

\section{CONSIDERACIONES FINALES}

Durante el Periodo Colonial, junto con los cambios sociales, económicos y demográficos; el urbanismo y territorio en los Andes Centrales fue transformado por los poderes imperiales. Varias de estas reformas se "construyeron" en torno a cambios en el espacio construido (asentamientos) y el espacio natural (paisaje). En este proceso, las prácticas religiosas de los grupos locales y foráneos se reformularon en un nuevo lenguaje que reinterpretaba los conceptos y las expresiones materiales, un ejemplo de ello son las distintas configuraciones que adquirió el orden y manejo del espacio en los pueblos de indios o reducciones.

Así, se generó un paisaje en el que los puntos geográficos de carácter sacro, los asentamientos, los edificios rituales, viviendas y límites territoriales de distintos periodos (inca y colonial), interactuaron en un mismo momento; y junto con ello, los pueblos pre-hispánicos y españoles se interrelacionaban en un nuevo orden; surgía el mundo andino-colonial. 


\section{REFERENCIAS BIBLIOGRÁFICAS}

\section{ARCHIVO ARZOBISPAL DE LIMA}

1650 Causa Criminal contra una yndia llamada Juana Ycha, viuda, de echizos y pactos expresos con un demonio llamado Apo Parato... Leg 3, Exp. 1., 31 fs. y carátula.

\section{ARCHIVO DEL OBISPADO DE HUACHO}

1769 Visitas Pastorales. Leg. 4, exp. 10, 9fs y carátula.

ACUTO, F.,

1999 Paisaje y dominación: la constitución del espacio social en el imperio inka. In A. Zarankin \& F. Acuto, eds. Sed Non Satiata; Teoría social en la arqueología latinoamericana contemporánea. Buenos Aires, 33-75.

2008 Materialidad, Espacialidad y Vida Social: Reinterpretando el Período PrehispánicoTardío de los Andes del Sur. In F. Acuto \& A. Zarankin, eds. Sed Non Satiata II; Acercamientos sociales en la arqueología latinoamericana. Córdoba: Encuentro grupo editor, 159-193.

APARICIO, Severo

2001 La Orden de la Merced en el Perú; estudios históricos. Cuzco: Provincia Mercedaria del Perú.

BENITO, José Antonio

2006 Libro de visitas de Santo Toribio de Mogrovejo (1593-1605). Introducción, transcripción y notas de José Antonio Benito. Lima: Pontificia Universidad Católica del Perú, Fondo Editorial.

BUENO, Cosme

1951 Geografía del Perú virreinal. Carlos Daniel Valcárcel, editor. Lima.

DURSTON, A.

1999 El proceso reduccional en el sur andino: confrontación y síntesis de sistemas espaciales. Revista de Historia Indígena, 4(1999-2000), $75-101$.

DUVIOLS, Pierre

1986 Cultura andina y represión. Procesos y visitas de idolatrías y hechicerías, Cajatambo, siglo XVII., Cuzco: Centro Estudios Rurales 
Andino Bartolomé de Las Casas.

1977 La destrucción de las religiones andinas (Durante la Conquista y la Colonia), México: Universidad Nacional Autónoma de México.

2003 Procesos y visitas de idolatría. Cajatambo, siglo XVII, Lima: Instituto Francés de Estudios Andinos-Pontificia Universidad Católica del Perú.

ESTENSSORO, J.C.

2001 EL simio de Dios. Los indígenas y la Iglesia frente a la evangelización del Perú, siglos XVI-XVII. Bulletin. Inst. fr. études andines, 30(3), 455-474.

GLOWACKI, M. \& MALPASS, M.

2003 Water, Huacas and Ancestor Worship: Traces of a Sacred Wari Lanscape. Latin American Antiquity, 14(4), 431-448.

GONZÁLES Y ASTUHUAMÁN

2012 Cultos, rituales y paisajes sagrados en los Andes Centrales, siglo XVII:Apo Parato, Junín. In Revista Haucaypata. Investigaciones arqueológicas del Tahuantinsuyo,(4), 71-96.

GOSE, P.

1996 Oracles, divine kingship, and political representation in the Inka state. Ethnohistory, 43(1),1-32.

2006 Mountains Historicized. Ancestors and landscape in the colonial Andes. In P. Dransart, ed. Kay Pacha; cultivating earth and water in the Andes. Oxford, 29-38.

2008 Invaders as ancestors: on the intercultural making and unmaking of Spanish colonialism in the Andes 1st ed., Toronto: University of Toronto Press.

GUTIÉRREZ, R.

1993 Las reducciones indígenas en el urbanismo colonial. In R. GUTIÉRREZ (coord.), ed. Pueblos de indios, otro urbanismo en la región andina. Quito: Abya-Yala, 11-63.

HAYDEN, Robert M., et al.

2011 The Byzantine Mosque at Trilye: A Processual Analysis of Dominance, Sharing, Transformation and Tolerance. History and Anthropology 22(1):1-17. 
HUERTAS, L.

1991 Pertubaciones Étnicas en Piura. In Bulletin. Inst. fr. études andines, 20 (2):489-500

HYSLOP, J.

1991 Observations about research on pre- historic roads in South America. In C. Trombold, ed. Ancient road networks and settlement hierarchies in the New World. Cambridge: Cambridge University Press, 28-33.

JONES, S.

2003 The Archaeology of Ethnicity; constructing identities in the past and present 2nd ed., London and New York: Routledge.

LEÓN, D.

2008 Evangelización y control social en la doctrina de Canta, siglos XVI y XVII. Lima: Universidad Nacional Mayor de San Marcos.

MACCORMACK, S.

1991 Religion in the Andes; Vision and Imagination in Early Colonial Peru, Princeton: Princeton University Press.

2004 Religion and Society in Inca and Spanish Peru. In The Metropolitan Museum of Art, ed. The Colonial Andes; tapestries and silverwork, 1530-1830. New York, 101-113.

MUMFORD, J.

2012 Vertical Empire: The General Resettlement of Indians in the Colonial Andes, Duke University Press.

RICE, P.M.

2012 Torata alta: an inka administrative center and spanish colonial. , 62901(1), 3-28.

SILLAR, B. \& DEAN, E.

2002 Identidad étnica bajo el dominio Inka: una evaluación arqueológica y etnohistórica de las repercusiones del estado Inka en el grupo étnico Canas. Boletín de Arqueología PUCP, 6, 205-264.

SPALDING, K.

1974 De Indio a Campesino; cambios en la estructura social del Perú colonial. Instituto de Estudios Peruanos, ed., Lima. 
1999 The Crises and transformations of invaded societies: Andean Area (1500-1580). In F. Salomon \& S. B. Schwartz, eds. The Cambridge History of the Native Peoples of the Americas. Cambridge: Cambridge University Press, 904-972.

TOLEDO, Francisco de

1965 "Memoria Felipe II". M. Jiménez de la Espada Relaciones geográficas de Indias, Perú, I. Biblioteca de Autores Españoles 183.

URTON, G.

1984 Chuta: el espacio de la práctica social en Pacariqtambo, Perú. Revista Andina, (3), 7-43.

VANVALKENBURGH, N.

2012 Building Subjects: Landscapes of Forced Resettlement in the Zaña and Chamán Valleys, Peru 16th-17th Centuries C.E. Harvard University.

VILLAR CÓRDOVA, P.

1935 Las culturas Pre-hispánicas del Departamento de Lima. Auspiciada por La H. Municipalidad de Lima. Lima.

WERNKE, S.

2013 Negotiated Settlements; Andean Communities and Landscapes under Inka and Spanish Colonialism. Florida: University Press of Florida.

\section{WERNKE, S.}

2007 Negotiating Community and Landscape in the Peruvian Andes: A Transconquest View. American Anthropologist, 109(1), 130-152. 